\title{
O LÚDICO NOS ADULTOS: UM ESTUDO EXPLORATÓRIO NOS FREQÜENTADORES DO CEPE - NATAL/RN
}

\author{
Andréa Francos Ferreira ${ }^{1}$ \\ Ana Karoliny da Cruz Vasconcelos ${ }^{2}$ \\ Cynthia Valéria Barbosa Gomes ${ }^{3}$ \\ Marcilma Galvão da Rocha ${ }^{4}$
}

\author{
${ }^{1}$ Graduanda do Curso Superior de Lazer e Qualidade de Vida. \\ andreafrancos@yahoo.com.br \\ ${ }^{2}$ Graduanda do Curso Superior de Lazer e Qualidade de Vida. anakarolinyv@bol.com.br \\ ${ }^{3}$ Graduanda do Curso Superior de Lazer e Qualidade de Vida. val803@hotmail.com.br \\ ${ }^{4}$ Graduanda do Curso Superior de Lazer e Qualidade de Vida
}

\section{RESUMO}

O presente artigo tem como objetivo analisar a manifestação do fenômeno lúdico nos adultos, que freqüentam o Clube dos Empregados da Petrobrás em Natal/RN. Tal estudo está pautado sob a concepção e perspectiva do lúdico, enquanto fenômeno social. Para se atingir o objetivo utilizou-se uma metodologia caracterizada como qualitativa, sendo, também, do tipo exploratória. Os dados foram coletados, através de diversas visitas ao local, durante o mês de maio de 2003, dentre as quais foram utilizados questionários de entrevistas com o dirigente da Instituição e os com usuários do Clube, além de observação não-participante a qual utilizou-se de métodos descritivos visando colher detalhadamente as características do objeto em estudo. Os resultados obtidos vieram evidenciar e dar veracidade às afirmações feitas pelos estudiosos do lazer, de que o ser humano, à medida que vai se tornando adulto deixa para trás o significado do lúdico, devido ao uso da racionalidade exacerbada e, também, por causa das convenções impostas pela sociedade.

Palavras-chave: CEPE/RN, Lúdico e Adulto.

\section{LE LUDIQUE DANS LES ADULTES: UNE ÉTUDE D'EXPLORATION DANS LES VISITEURS DE CEPE - NATAL/RN}

\section{LE RÉSUMÉ}

Le présent article a pour objectif analyser la manifestation du ludique pour phénomène chez les adultes qui fréquentent le Club des Employés de Petrobrás à Natal/RN. Une telle étude est gouvernée se pose la conception et perspective du ludique comme que phénomène social. Arriver à l'objectif il été utilisé une méthodologie caractérisé aussi comme qualitative du type d'exploration. Les données ont été rassemblés à travers plusieurs visites à l'endroit, pendant le mois de mai de 2003 parmi les quelles des questionnaires d'entrevues ont été utilisés avec le chef de l'Institution et les utilisateurs du club, aussi bien que l'observation non participant e qui s'est utilisé de méthodes descriptives qui cherchent à ramasser en détai les caractéristiques l'objet en étude. Les résultats obtenus sont venus manifester et vendre vrai lês affirmations des spécialistes du loisir lê quel preuvi qui l'être humain au fure t à mesure qu'il avone em age, prescinde du du à l'usage de la rationalité exacerbée et aussi à cause des conventions imposées par la société.

Les Mot Clefs: CEPE/RN, Lúdique et Adulte 


\section{O LÚDICO NOS ADULTOS: UM ESTUDO EXPLORATÓRIO NOS FREQÜENTADORES DO CEPE - NATAL/RN}

\section{CONTEXTUALIZANDO E CARACTERIZANDO O CEPE}

O Clube dos Empregados da Petrobrás - CEPE - localizado à avenida Airton Senna no bairro de Nova Parnamirim em Natal, foi fundado em 22 de abril de 1981, com o nome de Associação dos Empregados da Petrobrás, isto é, ASPETRO. Tal conquista foi fruto de reivindicações feitas pelos trabalhadores da Petrobrás que almejavam espaços que fossem destinados ao lazer. Com o passar do tempo, o clube mudou de nome, passando a se chamar CEPE/Natal devido à necessidade de padronizá-lo, diferenciando-se assim apenas pela cidade. O Clube da Petrobrás é apenas um no meio dos 36 CEPE’S existentes e espalhados por todo o território nacional que estão subordinados a uma única Federação.

Este clube atualmente atende tanto a funcionários da Petrobrás quanto aos portadores associados com seus títulos. Em seu quadro social conta com a ajuda de 29 funcionários distribuídos em diversas funções, dentre as quais destacam-se: a de gerente administrativo, auxiliar de escritório, encarregados de manutenção dos espaços e auxiliar de serviços gerais. A inserção desses profissionais se dá de várias maneiras, geralmente de acordo com a escolha do gerente administrativo em sua gestão, ora por processo seletivo do Sistema Nacional de Emprego (SINE), ora por indicação do Gerente. Além disso, há a terceirização de outros funcionários como as enfermeiras e os salva-vidas que prestam serviço ao Clube, estes últimos fazem parte do corpo de bombeiros. Um outro tipo de serviço que também é terceirizado é a dos bares e restaurante.

Quanto a sua estrutura e baseando-se na classificação de Camargo, o CEPE classifica-se como um macro-equipamento polivalente de lazer, porque além de apresentar uma enorme área verde, oferece aos seus associados espaços para vivenciar os diversos interesses culturais do mesmo, como por exemplo: exposições artísticas, espaços destinados às atividades físico-desportivas, sociais e intelectuais. Além disso, possui 02 piscinas, sendo uma para adulto e outra para criança, 01 campo de futebol oficial, 01 de mini-campo gramado, 01 campo de futebol de areia, 01 quadra polivalente, 01 quadra para tênis, 01 campo vôlei de areia, 02 salões sociais, 01 salão de jogos, vários toaletes e vestiários, bares, 01 parque infantil, salas destinadas à musculação e à ginástica, além de contar com uma granja que possui uma área verde ampla, mesas, cadeiras, churrasqueiras, bar, parque infantil e aquático.

No que se refere à manutenção e conservação dos espaços de lazer do Clube, pode-se dizer que é feita regularmente, pois há uma preocupação constante com a higienização do lugar, segundo afirma o gerente administrativo. O horário de atendimento da parte administrativa do CEPE funciona durante toda a semana das 07h e 30min às $19 \mathrm{~h}$ e $30 \mathrm{~min}$ e o clube durante os fins de semana e feriados, das $08 \mathrm{~h}$ às $17 \mathrm{~h}$. Tal espaço é freqüentado por pessoas da classe média de todas as faixas etárias. Oitenta e cinco por cento de sua estrutura física é adaptada para o acesso dos idosos e portadores de necessidades especiais, embora o clube ainda não disponha de nenhuma cadeira de rodas, para atender tais usuários. Apesar dessa dificuldade, a direção do clube prima em oferecer melhores condições de lazer para seus usuários, e atualmente está organizando uma sala de leitura completa, com acústica, livros, revistas, a fim de atender aos interesses de todos os seus associados. 
No que concerne sobre políticas de animação nos espaços de lazer deste Clube, observouse que este tipo de política é inexistente, pois o mesmo não dispõe de nenhum profissional habilitado que atenda esta falta. De acordo com depoimento prestado pelo gerente administrativo, o clube tem interesse em abrir estágios para tais profissionais, principalmente em se tratando dos acadêmicos do Curso de Lazer e Qualidade de Vida do CEFET/RN.

\section{FUNDAMENTANDO O LÚDICO}

Não se sabe ao certo quando se percebeu a ludicidade nos homens, mas alguns autores acreditam que este fenômeno tenha origem em épocas pré-históricas, quando o homem ainda era nômade.

Segundo Brunhs (1997, p.11), na vida cotidiana o lúdico é concebido da seguinte maneira:

Em seu sentido primeiro, vida cotidiana diz respeito às coisas que ocorrem na sucessão de todos os dias. Refere-se, portanto, ao que é habitual, corriqueiro, comum. Talvez, por isso, se construam algumas vezes em torno dela associações com aspectos de pouca ou nenhuma importância, inscrito no que é banal, pura trivialidade. Algo semelhante parece acontecer com as práticas lúdicas, não raro encaradas como contraponto de seriedade, reino de tudo que é inútil, improdutivo, vazio. Coisas para entreter quem não tem mais o que fazer.

Em outras palavras, para o senso comum o lúdico ainda é visto de forma preconceituosa e banal, tido como uma atividade que deve ser direcionada somente para crianças e idosos, já para Bartholo (2001, p.92), um dos estudiosos da área, a concepção de lúdico encontra-se paradoxalmente a esta, aparecendo da seguinte forma:

O lúdico e o criativo são elementos constituintes do homem que conduzem o viver para formas mais plenas de realização; são, portanto, indispensáveis para uma vida produtiva e saudável, do ponto de vista da auto-afirmação do homem como sujeito, ser único, singular, mas que prescinde dos outros homens para se realizar, como ser social e cultural, formas imanentes à vida humana.

No mundo moderno é mais freqüente presenciar a vivência do lúdico nas crianças e nos idosos. Um dos motivos que se leva a pensar dessa maneira é que, aparentemente, eles têm mais tempo livre para se dedicarem a tal atividade e também por que não estão comprometidos com o setor produtivo da sociedade, cuja seriedade é ponto fundamental.

Em se tratando dos adultos a sociedade contemporânea é mais severa, pois não os permite vivenciar a ludicidade plena, talvez isso ocorra porque se considera a fase adulta de extrema importância à produtividade, e também por ser o brincar, visto por esta sociedade capitalista como uma perda de tempo. Este mesmo adulto solidifica ainda mais esta idéia, porque ao preocupar-se com o seu futuro e sua sobrevivência sente a necessidade de trabalhar e acumular recursos financeiros para ter uma velhice mais segura. Este tipo de 
comportamento leva crer que é somente na terceira idade que ele poderá vivenciar a ludicidade.

No contexto capitalista, com enfoque na produtividade e no lucro a qualquer custo, enfatiza mais os atributos intelectuais e físicos do que os valores espirituais, tais como: sensibilidade, criatividade, senso estético, solidariedade, altruísmo, idealismo e humor. Nessa perspectiva, várias conseqüências danosas emergem, afetando exclusivamente aos adultos que interiorizam essa lógica de que é preciso trabalhar agora, para mais tarde ter "condições” de vivenciar a ludicidade. Ao analisar essas "condições”, nota-se um pouco de ambigüidade, pois o fato de acumular dinheiro, para o futuro, pode fazer com que o indivíduo perca as condições físicas e/ou mentais necessárias para sobreviver.

Diante disso, pode-se citar como exemplo um adulto que passou toda a sua vida trabalhando, pela manhã, à tarde, à noite e inclusive nos fins de semana, passando várias madrugadas acordado, usando e abusando de remédios e acumulando todo o stress do cotidiano, é inevitável e evidente que quando ele estiver disponível a vivenciar práticas lúdicas, não terá mais condições físicas, e todo o dinheiro poupado ao longo de sua vida, será deixado para os herdeiros.

Dentro deste contexto, é perceptível também, a existência de uma classe ainda mais estigmatizada e discriminada pela sociedade, tais como, as mulheres adultas, que possuem o acesso às vivências lúdicas ainda mais restritas que homens, como cita Marcellino (1995, p.51):

A rotina das tarefas domésticas, a preocupação com os filhos menores, a longa exposição aos veículos de comunicação de massa podem comprometer as atitudes dessas mulheres com relação ao lazer, a tal ponto de transformá-las em prisioneiras psicológicas, mesmo quando são vencidos os empecilhos físicos e econômicos para sua participação.

A dupla jornada de trabalho hoje assumida pelas mulheres e a maneira pela qual a mídia expõe o seu corpo privam-na de liberar a sua ludicidade, mesmo que seja uma mulher moderna as barreiras psicológicas permeiam seu cotidiano impedindo-as de ter lazer e de brincar espontaneamente.

Analisando uma outra visão, muitos adultos desprovidos de recursos financeiros e com uma baixa auto-estima sentem que suas vidas não têm mais sentido, nem mesmo quando são produtivos, com isso geram uma expectativa pessimista ao chegar a sua terceira idade. Pois se a vida não foi boa, quando jovem, porque será melhor quando for idoso?

Diante de todas essas considerações, nada mais justo que resgatar a ludicidade na vida do ser humano, a fim de que ele possa aproveitar intensamente todos os momentos de alegria, felicidade, criatividade e imaginação que existem dentro dos limites e das possibilidades do mundo atual. Por isso é tão importante o ambiente de lazer, como espaço apropriado para a vivência do lúdico, como cita Mello apud Marcellino (1995, p.31):

Um dos espaços possíveis para a recuperação do lúdico está nas atividades de lazer, uma vez que estas constituem um dos canais possíveis de transformação cultural e moral da sociedade, sendo, 
assim, instrumentos de mudança, mas instrumentos que podem ser acionados qualquer que seja a ordem social dominante.

Da mesma forma, somente a ludicidade pode resgatar a criatividade e criticidade dos indivíduos, fazendo com que sejam capazes de resistir às situações desumanizantes, levantando sua auto-estima e lhes dando motivos para viver em um país onde paira tanta injustiça social.

Segundo relata Santin (1994, p.87):

O lúdico e a ludicidade só serão compreendidos no seu acontecer. O lúdico se parece a uma sinfonia: ela precisa ser executada para ser vivida. Não é uma idéia intelectualizada que nos dá a compreensão da sinfonia. Ela não foi criada para se tornar conceito, mas para ser vivenciada mediante sua execução. $\mathrm{O}$ ato lúdico coloca-se na mesma esteira e, ainda, com uma grande diferença. Ele não precisa de partitura. Cada ato lúdico é novo e original, jamais repetido.

É na brincadeira que se vivencia o lúdico, conforme afirma Platão apud Pinto (2001), quando diz: "Você pode aprender mais sobre uma pessoa em uma hora de brincadeira do que em uma vida inteira de conversação", ou seja, por ser espontânea a brincadeira pode revelar sentimentos, comportamentos e verdades do ser humano que dificilmente seriam demonstrados num diálogo.

Assim, o lúdico assume uma grande importância na vida das pessoas, porque é capaz de estimular sensações, somente compreendidas por quem as sente quando estão brincando.

\section{ANALISE DOS DADOS: A MANIFESTAÇÃO DO LÚDICO NOS ADULTOS DO CEPE/RN}

A manifestação do fenômeno lúdico foi observada em todos os espaços oferecidos pelo CEPE, muito embora ela tenha aparecido em proporções totalmente desiguais, quando vivenciada pelo adulto. Assim acreditando que o lúdico é um fim em si mesmo, porque não busca nenhum outro objetivo a não ser o prazer de forma espontânea, verificou-se que ele, mesmo convivendo com tanta formalidade social, expressou-se nos adultos que freqüentam o CEPE através de gestos espontâneos, danças em rodas de samba, conversas informais nas mesas do bar, as quais constituíam-se de piadas, contos e anedotas.

Notou-se, ainda, que nas mulheres que freqüentam a Instituição, a ludicidade é mais restrita, por duas razões: primeira porque enquanto seus maridos se divertem, elas cuidam dos filhos; segunda porque existe inibição por parte de algumas em expor seu corpo em público, por se sentirem reprimidas por seus companheiros.

Observou-se, também, que a maioria dos adultos homens se contém, não se permitem agir de maneira espontânea, não expressam assim suas emoções, criatividade e ludicidade devido às exigências (obrigatoriedade) que se tem em seguir às normas impostas pela sociedade, que a fase adulta é a fase da seriedade, das obrigações. Contraditoriamente a isso percebeu-se de forma clara que alguns adultos quebram essas barreiras, não se incomodando com o julgamento dos outros, fazendo o que lhes convém, ou seja, chamam a 
atenção de todos que estão ao seu redor. Dessa forma acabam vivenciando a ludicidade plenamente dentro de um dos interesses do lazer - o social.

Fazendo uma análise dessa realidade com o universo teórico pode-se afirmar que o número de adultos que vivenciam a ludicidade é reduzido, devido ao uso exagerado da razão, idéia esta construída historicamente pelos homens como uma das condições básicas para pertencerem à humanidade como afirma Santin (1994 p.13):

A racionalidade foi proclamada como a especificidade exclusiva e única das dimensões humanas. O humano do homem ficou enclausurado nos limites da racionalidade. Ser racional e ter o uso da razão constituíram-se nos únicos pressupostos para assegurar os plenos direitos de pertencer à humanidade.

Ao longo do tempo, e em convivência com essa concepção, percebeu-se que a ludicidade é colocada para ocupar lugares periféricos da existência humana, de forma que a vivência do lúdico acaba sempre ficando em segundo plano, e o ideal da humanidade passa a ser a racionalidade, onde o homem é comparado a uma máquina viva, cuja função é produzir (trabalhar) e não viver, ou seja, "a vida passa a ter valor pelos produtos e resultados, não pelo fato de ser simplesmente vida” (SANTIN, 1994).

Uma outra observação que foi percebida diz respeito ao modo de ocupação dos adultos no clube. Há uma concentração de adultos nas áreas destinadas aos bares e música ao vivo (lazer social), de modo que por volta do meio-dia, os espaços voltados para o lazer físicodesportivo, intelectual e artístico ficam completamente vazios. Talvez isso aconteça por dois motivos: primeiro porque há um certo preconceito por parte dos próprios adultos em vivenciar a ludicidade e segundo porque não existe uma política de animação, capaz de atrair este público adulto. Para comprovar tal hipótese perguntou-se a três usuários do Clube o porquê dos adultos se restringirem apenas ao interesse social diante da oferta de tantos outros interesses e espaços de lazer. As respostas foram as seguintes:

"Já passei do tempo de ficar nas quadras e piscinas brincando, prefiro a conversa, a cerveja” - diz Gilson Praxedes, 40 anos.

"Acho melhor ficar conversando e tomando umas, é mais divertido" - diz Alaíde Oliveira, 48 anos.

"Falta de incentivo, ou seja, uma política de animação no clube" - diz Humberto, 30 anos.

Diante de tudo que foi exposto neste artigo constatou-se que a ludicidade aflora em qualquer idade, mas por causa das couraças sociais, dos preconceitos, das regras e da própria história do homem na sociedade esta ludicidade pouco é percebida nos adultos e quando existe é ridicularizada pelo próprio adulto ou pelo meio em que este está inserido. 


\section{BIBLIOGRAFIA}

BARTHOLO, Márcia Fernandes. O lazer numa perspectiva lúdica e criativa. In: Cinergis, Santa Cruz do Sul. V.2, n.1, p. 89-99, jan/jun, 2001.

BRUHNS, Heloísa Turini. Introdução aos estudos do lazer. Campinas, SP: Editora da UNICAMP, 1997.

GIL, Antônio Carlos. Métodos e técnicas de pesquisa social. $5^{\mathrm{a}}$. Ed. São Paulo: Atlas, 1999.

HUIZINGA, John. Homo ludens - o jogo como elemento da cultura. São Paulo, SP: Perspectiva, 2000.

MARCELLINO, Nelson Carvalho. Lazer e humanização. 2ª . Ed. Campinas, SP: Papirus, 1995.

Lazer e educação. Campinas, Papirus, 1987.

.Pedagogia da animação. Campinas, Papirus, 1991.

MARLI, Santa Pires (org). Brinquedoteca: A criança o adulto e o lúdico. $2^{\mathrm{a}}$ Ed. Petrópolis, RJ, Vozes, 2000.

PINTO Tânia Regina. Jogos de gente grande. O Estado de São Paulo, São Paulo, 21 ou. 2001.

Disponível

em <http://www4.estado.com.br/suplementos/casa/2001/10/21/casa003.html>. Acesso em: 10 jul. 2003.

RICHARDSON, Roberto Jarry. Pesquisa Social: métodos e técnicas. $3^{\text {a }}$. Ed. rev. e ampl. São Paulo: Atlas, 1999.

SANTIN, Silvio. Educação Física: da alegria do lúdico à opressão do rendimento. Porto Alegre, RS: ESEF - UFRGS, 1994.

SEVERINO, Antônio Joaquim. Metodologia do Trabalho Científico. 21 ed. rev. e ampl. São Paulo: Cortez, 2000. 